Atik Widiyanti, M. Mauludin Naja dan Catur Lega Wibisono: Pengaruh Mendia Tanam Terhadap Pengolahan Lindi TPA Kabupaten Sidoarjo Menggunakan Typha Latifolia

\title{
PENGARUH MEDIA TANAM TERHADAP PENGOLAHAN LINDI TPA KABUPATEN SIDOARJO MENGGUNAKAN Typha latifolia
}

\author{
Atik Widiyanti ${ }^{1}$, M. Mauludin Naja ${ }^{1}$ dan Catur Lega Wibisono ${ }^{2}$ \\ ${ }^{1}$ Program Studi Teknik Lingkungan, ${ }^{2}$ Program Studi Sistem Informasi, Universitas Nahdlatul Ulama \\ Sidoarjo, Sidoarjo 61218 \\ email:widiyantienviron@gmail.com
}

\begin{abstract}
Abstrak
Penduduk Kabupaten Sidoarjo saat ini mencapai lebih dari 2,279 juta jiwa. Peningkatan jumlah penduduk berbanding lurus dengan jumlah sampah yang dihasilkan. Setiap hari jumlah sampah yang masuk ke TPA rata-rata sebanyak 350 ton/hari. Akibatnya volume lindi yang dihasilkan juga meningkat. Tujuan penelitian ini untuk membandingkan pengolahan lindi menggunakan media kompos dan tanah. Tumbuhan yang digunakan adalah Typha Latifolia. Parameter yang diamati antara lain pH, suhu dan TDS. Penelitian dilakukan dengan sistem bacth reaktor dan volume lindi yang digunakan adalah 15 L dengan konsentrasi 519 mg/L COD. Parameter dianalisa setiap dua hari hingga hari kelima. Hasil penelitian menujukan pengolahan lindi dengan media kompos menghasilkan pH yang lebih tinggi daripada media tanah yaitu 8 sedangkan media tanah 7. Dari analisa suhu juga menunjukkan suhu lebih tinggi dari reaktor media kompos dibanding reaktor media tanah yaitu $31^{\circ} \mathrm{C}$ pada hari ketiga sedangkan di media tanah $28^{\circ} \mathrm{C}$. Namun hasil analisa TDS yang dihasilkan lebih rendah dengan media tanah dibanding media kompos terutama mulai hari ketiga yaitu sebesar 104 ppm sedangkan 145 ppm pada media tanah.
\end{abstract}

Kata kunci: bacth reaktor, lindi, Typha latifolia, vertical free flow

\begin{abstract}
The population of Sidoarjo regency more than 2.279 million people. The increase in population is directly proportional to the amount of waste produced. Everyday the amount of waste that goes into landfill is 350 tons/day. As a result the volume of leachate produced also increases. The purpose of this study was to compare the leachate treatment using compost and soil in media. The plant used is Typha latifolia. Parameter observed ware $p H$, temperature and TDS. The study in bacth reactor and the volume of leachate used was $15 \mathrm{~L}$ with concentration of $519 \mathrm{mg} / \mathrm{L}$ COD. Parameters are analized every two day until the fifth day. The results of the study aimed at leachate processing with compost media producted a higher ph than soil media is 8 while the soil media 7. Temperatur analysis also showed higher temperatures than compost media reactor compared to the soil media reactor which was $31^{\circ} \mathrm{C}$ on the third day while in soil media $28^{\circ} \mathrm{C}$. However, the result of analysis of TDS produced are lower with soil media than compost media, especially starting on the third day which is equal to 104 ppm while 145 ppm in soil media.
\end{abstract}

Keyword: bacth reaktor, leachate, Typha latifolia, vertical free flow 


\section{PENDAHULUAN}

Pertumbuhan penduduk Kabupaten Sidoarjo mencapai $1.6 \%$ setiap tahunnya. Pertumbuhan yang sangat cepat berbanding lurus dengan jumlah sampah yang digunakan. Sampah yang masuk ke TPA (Tempat Pemrosesan Akhir) Kabupaten Sidoarjo mencapai 350 ton/hari. Lindi adalah cairan hasil dekomposisi tumpukan sampah, yang terbentuk melalui presipitasi air hujan yang masuk ke dalam tumpukan sampah dan uap air yang berada di dalam tumpukan sampah (Roux, 2013). Lindi mengandung banyak senyawa organik maupun logam berat. Menurut Aucott (2006), lindi mengandung berbagai bahan pencemar antara lain $1800 \mathrm{mg} / \mathrm{L}$ Total Dissolved Solids (TD), $350 \mathrm{mg} / \mathrm{L}$ Suspended Solids (SS), $1,4 \mathrm{mg} / \mathrm{L}$ sulfida, $65 \mathrm{mg} / \mathrm{L}$ ammonia $\left(\mathrm{NH}_{4}-\mathrm{N}\right), 1900 \mathrm{mg} / \mathrm{L}$ BOD dan $3800 \mathrm{mg} / \mathrm{L}$ COD (Sarudji, 2007). Selain itu terdapat logam berat seperti: Arsen (As), Barium (Ba), Kadmium (Cd), Kromium $(\mathrm{Cr})$, Timbal $(\mathrm{Pb})$, Merkuri $(\mathrm{Hg})$, Selenium $(\mathrm{Se})$, perak (Ag), Nikel (Ni), Copper $(\mathrm{Cu})$ dan Zinc (Zn). Lindi dapat menyebabkan dampak negatif pada kesehatan (Paramitha, 2008). Seperti yang terjadi pada daerah Khud Mai Thailand, masyarakat disana yang mengaku mengalami gangguan psikologis dan penurunan kesehatan akibat lindi yang dihasilkan TPA On-nuch (Watananugulkit et al., 2003).

TPA Kab. Sidoarjo kini menjadi salah fokus pembangunan pemerintahan daerah. TPA ini berada di daerah Kec. Jabon Kab. Sidoarjo dengan luas sekitar 8 Ha. TPA Kab.Sidoarjo masih menggunakan sistem open dumping dalam pengolahan sampah. TPA Kab. Sidoarjo juga menghasilkan lindi yang sangat besar dengan konsentrasi BOD, $\mathrm{COD}, \mathrm{NH}_{3}-\mathrm{N}$ dan Phosfat yang tinggi (Widiyanti, 2013). TPA Kab. Sidoarjo memiliki 2 bak penampung lindi berdimensi 10x 5 x 5 m. Kasus pencemaran lindi pernah terjadi di daerah sekitar TPA Kab. Sidoarjo, diketahui 60 ha sawah telah tercemar lindi yang dihasilkan TPA (Kompas, 2012). Oleh karena itu diperlukan pengolahan untuk lindi yang dihasilkan.

Salah satu pengolahan lindi adalah menggunakan fitoteknologi, yaitu penggunaan tanaman sebagai alat pengolah pencemar lingkungan. Typha latifolia merupakan tumbuhan yang telah diketahui mampu menurunkan konsentrasi COD, BOD dan TSS pada limbah domestik (Suhendrayatna et al., 2012). Selain itu penggunaan sistem wetland dengan Typha latifolia mampu meningkatkan rasio BOD/COD pada effluen lindi (Widiyanti et al., 2018). Menurut Mangkoedihardjo dan Permatasari (2012), diketahui dengan penambahan kompos Echinodorus palaefolius var latifolius memiliki kemampuan evapotranspirasi paling tinggi dibandingkan Ipomoea pes-caprae dan Salvinia molesta Mitchell. Selain itu, tumbuhan juga menghasilkan bahan organik yang dapat meningkatan rasio biodegradable yang disebut eksudat (Mangkoedihardjo dan Samudro, 2010). Pada penelitian ini bertujuan untuk mengetahui pengaruh media tanam terhadap kualitas lindi TPA Kab. Sidoarjo. Hasil penelitian menujukan pengolahan lindi dengan media kompos menghasilkan $\mathrm{pH}$ dan suhu yang lebih tinggi daripada media tanah. Namun hasil analisa TDS yang dihasilkan lebih rendah dengan media tanah.

\section{METODE}

\subsection{Waktu dan Tempat Penelitian}

Penelitian dilaksanakan di

Laboratorium Teknik Lingkungan Universitas Nahdlatul Ulama Sidoarjo pada bulan Juni 2018.

\subsection{Alat dan Bahan yang di Butuhkan Penelitian}

Bahan yang digunakan dalam penelitian ini antara lain lindi yang diambil dari TPA Kab. Sidoarjo, media tanam berupa kerikil, pasir, tanah dan kompos. Tumbuhan yang digunakan adalah Typha latifolia. Reaktor fitoremediasi berdimensi $30 \times 30 \times 50 \mathrm{~cm}$.

\subsection{Metode Penelitian}

a. Metode penelitian ini sebagai berikut: 1.Tahap aklimatisasi

Typha latifolia diambil dari wetland yang ada di sekitar kampus lalu ditumbuhkan selama tujuh hari pada tangki 
Atik Widiyanti, M. Mauludin Naja dan Catur Lega Wibisono: Pengaruh Mendia Tanam Terhadap Pengolahan Lindi TPA Kabupaten Sidoarjo Menggunakan Typha Latifolia

plastik bervolume $40 \mathrm{~L}$ yang berisi media kerikil, pasir, dan tanah.

2. Uji fitoremediasi

Uji fitoremediasi dilakukan menggunakan 2 reaktor yang telah berisi media tanam. Satu reaktor menggunakan media kerikil, pasir dan kompos, reaktor kedua menggunakan media kerikil, pasir dan tanah. Media diisikan pada reaktor dengan total ketebalan $30 \mathrm{~cm}$ (Gambar 1.). Kedua reaktor ditanami Typha latifolia masingmasing 5 batang. Uji Fitoremediasi menggunakan sistem bacth reaktor selama lima hari. Lindi diambil diencerkan hingga konsentrasi COD $591 \mathrm{mg} / \mathrm{L}$. Debit yang digunakan adalah $15 \mathrm{~L} /$ hari. Typha latifolia ditanam $10 \mathrm{~cm}$ dari permukaan media. Pengambilan sampel dilakukan setiap dua hari hingga hari keenam lalu dianalisa $\mathrm{pH}$, suhu dan TDS.

b. Metode Analisa Parameter

1. $\mathrm{pH}$

Analisa ph dilakukan dengan menggunakan $\mathrm{pH}$ meter. $\mathrm{pH}$ meter dimasukkan pada sampel effluen selama 5 menit, kemudian dibaca perubahan warna sesuai indikator yang ada pada kotak $\mathrm{pH}$ meter.

1. Suhu

Analisa suhu dilakukan dengan menggunakan termometer air alkohol. Termometer diletakkan pada bak effluen selama 5 menit, selanjutnya dibaca perubahannya tanpa termometer diangkat kepermukaan bak effluen.

\section{TDS (Total Dissolved Solids)}

Analisa konsentrasi TDS (Total Dissolved Solids) dilakukan menggunakan TDS meter. TDS meter dicelupkan pada sampel effluen selama 10 menit, hingga menunjukkan nilai TDS.

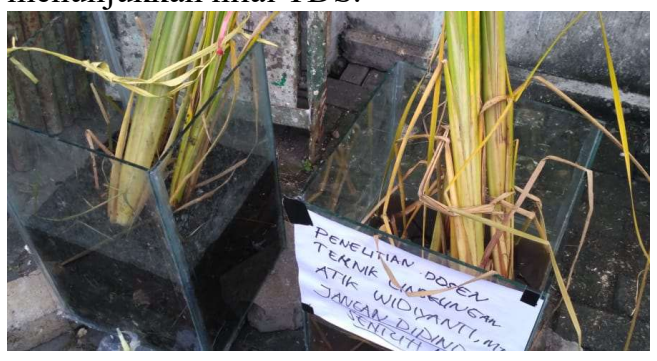

\section{Gambar 1. Uji Fitoremediasi \\ 1.4. Metode Pengumpulan dan Analisa Data}

Data yang diperoleh berupa data primer, yang akan disajikan dalam bentuk tabel dan grafik. Kemudian dilakukan pembahasan dengan mengevaluasi, menguraikan dan menyelidiki hasil yang telah diperoleh dengan membandingkan penelitian terdahulu.

\section{HASIL DAN PEMBAHASAN}

Lindi merupakan cairan yang dihasilkan dari timbulan sampah. Lindi TPA Kab. Sidoarjo selama ini belum terolah dengan baik. Akibatnya beberapa tahun yang lalu sawah di sekitar TPA Kab. Sidoarjo tercemari. Penelitian ini dilakukan dengan melakukan pengolahan lindi agar kualitasnya lebih baik. Penelitian dilakukan dengan menggunakan Typha latifolia yang ditanam pada 2 yaitu media kompos dan media tanah. Parameter yang diukur adalah $\mathrm{pH}$, suhu dan TDS. Penelitian dilakukan hingga hari ke-lima. Hasil analisa pengukuran $\mathrm{pH}$ terdapat adanya perbedaan antara reaktor media kompos dan media tanah (Tabel 1.).

Tabel 1. Hasil Pengukuran $\mathrm{pH}$

\begin{tabular}{ccc}
\hline Hari Ke- & Media Kompos & Media Tanah \\
\hline 1 & 8 & 7 \\
3 & 8 & 7 \\
5 & 8 & 7 \\
\hline
\end{tabular}

Berdasarkan Tabel 1. menunjukkan bahwa $\mathrm{pH} 8$ pada reaktor dengan media kompos dan stabil hingga hari kelima. Sedangkan pada reaktor dengan tanah $\mathrm{pH}$ nya sebesar 7 hingga hari kelima. Dengan proses fitoremediasi $\mathrm{pH}$ tersebut dapat diturunkan atau dinaikkan mendekati $\mathrm{pH}$ netral. Penambahan kompos selama lima hari memberikan $\mathrm{pH}$ yang lebih tinggi, mungkin karena kompos pada media mengalami serangkaian reaksi kimia dan merubah senyawa kompleks menjadi senyawa sederhana sehingga menyebabkan kenaikan pH. Menurut Siregar et al. (2014), menjelaskan bahwa penambahan kompos, baik kompos yang berasal dari sampah rumah tangga maupun kompos yang berasal 
dari sampah kota mampu menaikkan $\mathrm{pH}$

tanam untuk proses fitoremediasi penghilangan logam $\mathrm{Pb}$ dan $\mathrm{Cd}$. Konsenrasi $\mathrm{Ph}$ pada lindi berpengaruh pada konsentrasi TDS maupun TSS. Menurut Rafizul dan Alamgir (2012), menyatakan bahwa Ph asam dapat menyebabkan meningkatkan kelarutan zat organik maupun anorganik sehingga konsentrasi TDS dan TSS menjadi tinggi.

Hasil analisa suhu pada 2 reaktor (reaktor media kompos dan media tanah) menunjukkan bahwa suhu pada reaktor dengan media tanah lebih rendah dibanding reaktor dengan media kompos

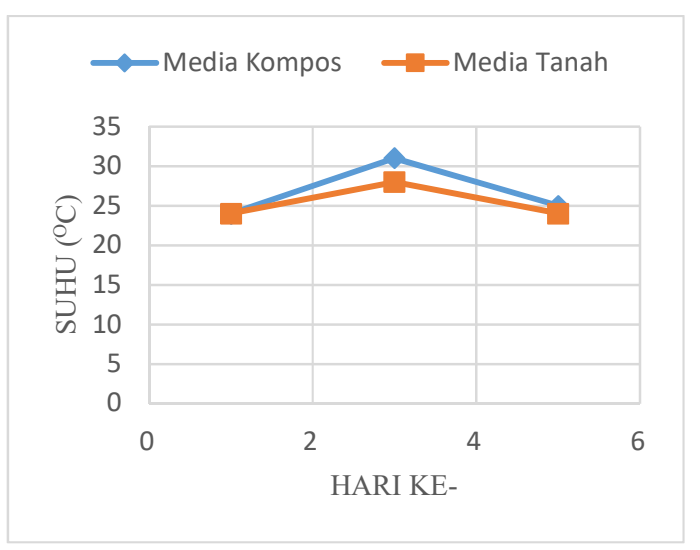

Gambar 2. Hasil Pengukuran Suhu

Kenaikkan suhu pada media, mungkin dikarenakan kompos mengalami berbagai reaksi kimia sehingga suhu pada media tanampun menjadi meningkat. Pada hari kelima suhu reaktor dengan kompos cenderung menurun hingga mendekati suhu reaktor dengan tanah. Hal ini mungkin dikarenakan reaksi kimia yang disebabkan oleh kompos menurun sehingga suhu reaktor juga menurun. Menurut Notodarmojo (2005), kompos bersifat hidrofilik sehingga dapat meningkatkan kemampuan tanah. Selain itu pemberian kompos juga meningkatkan aktifitas remediasai karena kompos mengandung jumlah mikrobia yang besar.

Hasil analisa TDS diperoleh bahwa pada hari pertama effluen reaktor dengan media kompos konsentrasi TDS lebih rendah dibanding reaktor dengan media tanah. Sedangkan pada hari ketiga dan kelima effluen reaktor dengan media tanah memiliki konsentrasi TDS yang lebih rendah dibanding reaktor dengan kompos (Gambar 3.)

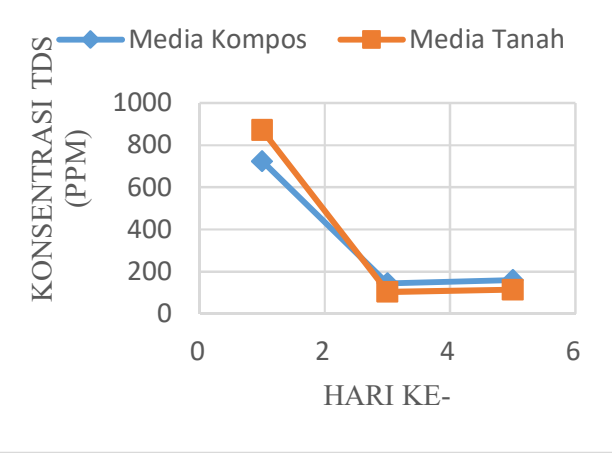

Gambar 3. Hasil Pengukuran TDS

Jenis media tanam pada reaktor sangat mempengaruhi degradsi atau penurunan kadar pencemar. Pasir dan kerikil merupakan media telah terbukti efektif sebagai media filtrasi. Pada penelitian ini bagian bawah kedua reaktor terdiri atas kerikil dan pasir yang merupakan media penyangga dan membantu menurunkan kadar pencemar melalui proses filtrasi. Pada bagian atas media merupakan media yang sangat penting dalam degradasi pencemar, karena pada bagian atas media terdapat banyak mikroorganisme maupun mikrofauna yang aktif dalam mendegradasi bahan pencemar (Hendrawan et al., 2014).

\section{KESIMPULAN}

Berdasarkan penelitian ini dapat disimpulkan bahwa fitoremediasi lindi TPA Kab. Sidoarjo menggunakan Typha latifolia dengan media kompos menghasilkan $\mathrm{pH}$ yang lebih tinggi daripada media tanah yaitu 8 sedangkan media tanah 7. Dari analisa suhu juga menunjukkan suhu lebih tinggi dari reaktor media kompos dibanding reaktor media tanah yaitu $30^{\circ} \mathrm{C}$ pada hari ketiga sedangkan di media tanah $28^{\circ} \mathrm{C}$. Namun hasil analisa TDS yang dihasilkan lebih rendah dengan media tanah dibanding media kompos terutama mulai hari ketiga yaitu sebesar 104 ppm sedangkan 145 ppm pada media tanah. 
Atik Widiyanti, M. Mauludin Naja dan Catur Lega Wibisono: Pengaruh Mendia Tanam Terhadap Pengolahan Lindi TPA Kabupaten Sidoarjo Menggunakan Typha Latifolia

\begin{aligned} \hline 5. UCAPAN TERIMA KASIH & Nahdlatul Ulama Sidoarjo, Kepala \\ Ucapaan kami sampaikan kepada & Laboratorium Universitas Nahdlatul Ulama \\ semua pihak yang membantu pelaksanaan & Sidoarjo dan mahasiswa TL Universitas \\ penelitian ini antara lain LPPM Universitas & Nahdlatul Ulama Sidoarjo. \end{aligned}

\section{DAFTAR PUSTAKA}

Aucott, M. 2006. The fate of heavy metals in landfills: A Review. Industrial Ecology, Pollution Prevention and the NY-NJ Harbor

Hendrawan, D., M.F. Fachrul., B. Iswanto., P. Purwaningrum, 2014. Pengaruh Media Dalam Lahan Basah Buatan Tipe Subsurface Flow System terhadap E. Coli. Laporan Penelitian Jurusan Teknik Lingkungan Universitas Trisakti

Kompas. 2012. Limbah Cair TPA Sampah Sidoarjo Cemari Sawah

Diakses dari http://www.tempo.co/read/news/2012/02/10/180383144/Limbah-CairTPA-Sampah-Sidoarjo-Cemari-Sawah

Mangkoedihardjo, S. dan D. Permatasari. 2012. Hospital Wastewater Treatment In Evapotranspiration System. International Journal Of Academic Research Vol. 4. No. 1.

Mangkoedihardjo S. dan G. Samudro. 2010. Fitoteknologi Terapan. Graha Ilmu: Yogyakarta

Notodarmojo, S. 2005. Pencemaran Tanah dan Air Tanah. Penerbit ITB. Bandung

Paramitha, I. and Sudarmaji.2008. Hubungan Jarak Terhadap Kualitas Kimia Air Tambak Dan Keluhan Kesehatan Masyarakat Konsumen Ikan Hasil Tambak Di Sekitar Tempat Pembuangan Akhir Sampah Benowo. Jurnal Kesehatan Lingkungan, Vol.4, NO.2

Rafizul, I.M., dan Alamgir, M. 2012. Characterization and Tropical Seosonal Variation of Leachate: Result from Landfill lysimeter studied.

Roux, L. 2013. Guidelines For Leachate Control. Diakses dari http://www.dwaf.gov.za/Documents/Policies/WDD/LeachateControl.pdf (23-01-2013).

Sarudji, D. 2007. Stabilization of Ammonia and Organic Matter Containing Leachate Using Cement and Clay. Journal Applied Science in Environmental Sanitation. Vol 2 (2): 67-69

Siregar, D., Abdul. R., L. Musa., 2014. Pengaruh Perlakuan Kompos Sampah Kota Dan Kompos Residu Rumah Tangga Pada Tanah Terhadap Kadar Pb Serta Cd Tersedia Dan Produksi Sawi (Brasillia oleraceae L.). urnal Online Agroekoteknologi . Vol.2, No.3 : $1106-1113$

Suhendrayatna, Marwan, R. Andriani, Y. Fajriana and Elvitriana. 2012. Removal of Municipal Wastewater BOD, COD, and TSS by Phytoreduction: A Laboratory-Scale Comparison of Aquatic Plant at Different Species Typha latifolia and Sachrarum Spotaneum. International Journal of Engineering Innovative Technology (IJEIT). Vol.2 issue 6

Watananugulkit, R., C. Intim, P. Patnukao and P. Tansathit. 2003. Assessment of Impact on Water Quality of Leachate at On-nuch Disposal Site Center in Bangkok. J. Sci. Res. Chula. Univ., Vol.28

Widiyanti, Atik. 2013. Pengaruh Selenium dan Jumlah Scirpus grossus Untuk Efisiensi Pengolahan Lindi TPA Kabupaten Sidoarjo Menggunakan Variasi Komposisi Media. Tesis Teknik Lingkungan. ITS

Widiyanti, Atik., Wibisono, Catur L., dan R. Marizatur. 2018. Pengaruh Typha latifolia pada Rasio BOD/COD Lindi TPA Kabupaten Sidoarjo. Conference Proceeding on Waste Treatment Technology 